\title{
Nutrition and cholesterol gallstones
}

\author{
By T. S. Low-BEer, Selly Oak Hospital, Birmingham B29 $6 \mathfrak{F D}$ \\ '. . and of our pleasant vices, makes instruments to plague us' \\ King Lear
}

Popular and medical tradition would support a link between diet and gallstones. However, scientific verification is bedevilled by the problems of studying a disease where the epidemiology and natural history are poorly documented, and the majority of people with gallstones die with them undiagnosed (Zahor et al. 1974).

Epidemiological studies are based largely on necropsy results and the potential fallacies in this source of information are well known: the segment of the population dying in hospital, the selection of these undergoing post mortem examination and the recording of the findings varies greatly between different studies. Similarly, operative rates are likely to provide a distorted reflection of epidemiology, and cholecystographic surveys have been small in number and scale. Large-scale ultrasonographic surveys are soon likely to be published, and are bound to improve our knowledge of gallstone disease and its causes.

At the experimental level, the physiology of the biliary system shows much species variation, and although gallstones can be produced by dietary manipulation in certain laboratory animals, cholesterol-rich gallstones have not been produced experimentally in man. Within these constraints, what light have epidemological and experimental work thrown on the dietary influences on human cholesterol gallstone disease?

Cholesterol-rich stones account for $80-85 \%$ of gallstones in industrialized nations, and can only form when the gall-bladder contains cholesterol-supersaturated bile. Much interest has centred on cholesterol intake, and on dietary factors such as overeating and obesity, which influence lipid metabolism, for cholesterol and bile acid in bile constitute the principal route for cholesterol excretion.

A third to a half of newly synthesized or absorbed cholesterol is transformed into bile acids. Perhaps half the body's cholesterol is synthesized in the liver and exported either into the sinusoid or into the canaliculus as bile acid or cholesterol itself. The remaining cholesterol arrives at the sinusoid as chylomicrons and very-low-density lipoproteins or their remnants, low-density lipoproteins and the high-density lipoproteins. Cholesterol ester probably forms a separate functional compartment from non-esterified cholesterol.

Normally less than $5 \%$ of bile acid secreted into bile is newly synthesized. The rest is derived from that recycled enterohepatically. This information is still too incomplete to be useful in explaining how the partition of excreted liver cholesterol 
into biliary cholesterol or bile acid under some circumstances leads to supersaturated bile. Nutritional influences on gallstone formation cannot yet be explained in pathophysiological terms (Low-Beer, 1977).

\section{Cholesterol intake}

Two American studies raised the cholesterol content of bile by adding cholesterol to the diet for 3 weeks. One study has been published in abstract form (Lee et al. 1983), the other involved a liquid formula diet which caused serum as well as biliary cholesterol concentrations to rise (DenBesten et al. 1973). Serum and biliary cholesterol concentrations are not known to be positively correlated, and the relation may even be inverse. In contrast, two Scandinavian studies (Dam et al. I971; Andersen \& Hellstrom, 1980) failed to change bile cholesterol saturation by feeding five or more eggs a day for 2 and 6 weeks respectively. Dietary cholesterol fails to show up as an important risk factor in dietary surveys (Friedman et al. 1966; Scragg et al. 1984).

\section{Hyperlipidaemia}

Hypercholesterolaemic individuals are not at an increased risk of developing gallstones. However, a cholesterol-lowering diet high in dietary polyunsaturated fats probably does raise the risk of development of gallstones in certain hyperlipidaemic individuals (Sturdevant et al. 1973).

A relation between raised serum triglyceride concentration and gallstone prevalence has been demonstrated in Stockholm (Ahlberg et al. 1979). Most patients with hyperlipoproteinaemia type IV and, to a lesser extent, type IIb patterns, have features more in keeping with an acquired than a familial disease, are often obese and respond to dietary restriction of energy and refined carbohydrates; this suggests a relation to overeating. While these studies have not always been confirmed (Bateson, 1980), and have been criticized on the basis of inappropriate controls, the connection has support. For instance, hypertriglyceridaemia has been found with increased frequency in gallstone patients (Bell et al. 1973; Kadziolka et al. 1977; van der Linden \& Bergman, 1977; Ahlberg, 1979); a low serum concentration of high-density lipoprotein, also a diet-related phenomenon, has been shown to be common in patients with gallstones (Petitti et al. 1981, Thornton et al. 1981).

\section{Obesity and energy excess}

This is the most popularly held epidemiological relation to gallstones. While on theoretical grounds continued 'overeating' is not a necessary concomitant of obesity (Keen et al. 1979), most obese people probably eat more on average than those of average weight. What is the evidence for a link with gallstones?

The Pima Indians of Arizona hold the world record for gallstone prevalence, so that at 30 years of age over $70 \%$ of the women will already have gallstones (Sampliner et al. 1970). Most of them are obese, many with diabetes. In a people so overweight to start with, it is not surprising that the degree of obesity is 
unrelated to gallstones, but obesity correlates with bile cholesterol saturation. Obesity was shown as a risk factor in Framingham, Massachusetts (Friedman et al. 1966) and, in women under 50 years of age, in the impressive case-control study from Adelaide (Scragg et al. 1984). This confirmed previous Australian work: thinness has been shown to be protective in men, and in women under 40 years, in a necropsy study (Newman \& Northup, 1959). Gallstone patients averaged $5.5 \mathrm{~kg}$ heavier than matched controls in another study (Burnett, 1971). Of the many other studies showing this relation, the necropsy study of $85 \%$ of the residents of Prague and Malmo who died during the years 1963-1966 (Zahor et al. 1974), is most convincing in showing a greater mean body-weight for gallstone patients of both sexes in every decade from 50 to 90 years, and also a significantly increased mean skin-fold thickness in gallstone disease. Many studies have shown increased bile cholesterol saturation in obese people, which decreases after slimming (e.g. Bennion \& Grundy, 1975; Mabee et al. 1976; Angelin et al. 1981).

Strong though this evidence is, many patients with gallstones are slim, many obese people have no gallstones (Sedaghat \& Grundy, r980), and societies exist where obesity is common but gallstones are rare (Heaton, 1979). Obesity is therefore undoubtedly a factor in the aetiology of gallstones, especially in younger women, but must require other environmental and maybe genetic factors to precipitate gallstones.

Energy intake is more difficult to study than obesity. Sarles' group in Marseilles (Sarles et al. 1969, 1971) and a study from Nova Scotia (Williams et al. 1977) have shown a high energy intake in gallstone patients, but several other studies have not shown this. Generally the studies have not been definitive in size or quality.

Postcholecystectomy T-tube patients who increased their energy intake rapidly augmented the cholesterol saturation of their bile (Sarles et al. 1971). One hundred and one women with gallstones were carefully matched for age, race and social class with 10r healthy women, all from Marseilles, and questioned about what their diet had been like during a typical I week period before the disease was evident (Sarles et al. 1969). Their calculated energy intake was 10.4 MJ/d (2495 $\mathrm{kcal} / \mathrm{d})$ compared with $9.1 \mathrm{MJ} / \mathrm{d}(2163 \mathrm{kcal} / \mathrm{d})$ in the controls $(P=0.0005)$. Patients ate significantly less vegetables and fruit $(2.6$ v. 3.0 and 6.3 v. $7.5 \%$ of energy respectively) and more bread ( $20 v .17 .5 \%$ dietary energy) and took less time to eat their meals than the controls (Sarles et al. 1969).

A recent Adelaide study by Scragg et al. (1984) used a semiquantitative food-frequency questionnaire to compare the diets of 267 patients at the time of gallstone diagnosis with 600 controls, $24 \mathrm{I}$ of them individually matched from the community, some presumably with undiagnosed gallstones. On average $20 \%$ more energy was consumed by gallstone patients under 50 years of age than by their matched controls. Consumption of $2 \cdot 1 \mathrm{MJ} / \mathrm{d}(500 \mathrm{kcal} / \mathrm{d})$ more than the controls increased the relative risk of gallstones by 2.7 and $\mathrm{I} \cdot 5$ fold in 20-year-old women and men respectively. This risk was found to fall progressively and consistently with every decade, so that by the age of 40 years in men and 60 years in women, the risk had become greater in those who ate less. This study is not the first to find 
obesity lithogenic only in younger people. Scragg et al. (1984) could find no link between obesity and energy intake.

These trends are not detectable in the unmatched hospital controls. This emphasizes how the results of such a study depend on the nature of the control population selected for comparison.

\section{Dietary fat}

Dietary questionnaires about fat intake in people who know they have gallstones present the difficulty that fat is popularly thought to be 'bad for you' and to bring on symptoms. Fat and energy intake were closely correlated with each other in the Adelaide study (Scragg et al. 1984), and intake of fat, while higher in the younger gallstone patients, was not a risk factor after middle age. However, altering the amount or type of fat in the diet has no consistent effect in short-term experiments (Sarles et al. 1969; Dam et al. 1971).

\section{Refined carbohydrate and reduced fibre intake}

As long ago as 1892 , Osler suggested a role for sweet foods in the aetiology of gallstones. Cleave (1974), Burkitt \& Tunstall (1975) and Heaton (1975) have all emphasized the nutritional effects of removing the fibrous components of plant foods, especially in the preparation of sugar, sugary drinks and white flour. The postulated consequences have been diseases associated with involuntary overnutrition, accelerated intestinal absorption and constipation.

Experimentally, Thornton et al. ( $(983 a)$ carried out a 6-week crossover study on thirteen patients with asymptomatic gallstones who alternated a diet rich in unrefined, full-fibre foods such as wholemeal bread, fruit and vegetables, with an ad lib. diet rich in fibre-depleted foods and containing $28 \%$ more energy. The mean cholesterol saturation index was $\mathrm{I} \cdot 5$ on the $a d$ lib. diet and $\mathrm{I} \cdot 2$ on the high-fibre, low-sugar diet. Body-weight averaged $\mathrm{I} \cdot 4 \mathrm{~kg}$ higher after the ad lib. diet, in keeping with Cleave's hypothesis (Cleave, 1974).

To isolate and change a single component in a dietary study is virtually impossible. In an attempt to determine whether the results of Thornton et al. $\left(1983^{a}\right)$ were due to increased sugar and energy contents of their lithogenic diet, or its low fibre content, Werner et al. (1984) showed that alternating diets which differed markedly in their sucrose and energy contents, but much less in the fibre content, had no effect on bile composition. Fibre content is therefore likely to have been the greatest influence in the first of the two experiments. Perhaps the results may have been different if the patients studied had not already had gallstone disease.

That sugar content of the diet may indeed constitute a risk for gallstone disease is suggested by Scragg's Adelaide study (Scragg et al. 1984). With an excess of sugar over the matched controls, mainly as drinks and sweets, of 20,40 and $60 \mathrm{~g} / \mathrm{d}$, the gallstone risk increased $1 \cdot 5-, 2 \cdot 0-$ and $3 \cdot 0$-fold respectively. As with the other dietary influences arising out of this study, the effect of sugar was greater in 
younger subjects, but was still significant in women aged $50-70$ years. By contrast, differences in fibre intakes were unimpressive.

Fibre intakes were lower in gallstone patients than controls in a Canadian study (Smith \& Gee, 1979), and those with gallstones where shorter and plumper, and ate less energy as well as fibre.

\section{The colon, constipation and gallstones}

Varieties of food fibre differ markedly in their effects on alimentary function and nutrition. Fibre is extensively 'digested' by the colonic flora, and wheat bran, for instance, affects colonic function much more than small intestinal function. Wheat bran supplements influence colonic transit, increase faecal solid and liquid bulk, and probably lower the $\mathrm{pH}$ of the colonic contents. Bran has generally been shown to decrease biliary deoxycholate content and cholesterol saturation when these are high to start with (Pomare \& Heaton, 1973; Pomare et al. 1976; McDougall et al. 1978; Watts et al. 1978). The proportion of secondary bile acid in bile correlates significantly with cholesterol saturation (van der Linden \& Bergman, 1977; Hofmann et al. 1982). When small doses of deoxycholate are administered, cholesterol content and saturation of bile increases (Low-Beer \& Pomare, 1975). Depleting biliary deoxycholate by reducing its formation or absorption using metronidazole (Low-Beer \& Nutter, 1978), bran (Pomare et al. 1976; McDougall et al. 1978; Watts et al. 1978) or lactulose (Thorton \& Heaton, 198r) lowers a raised cholesterol saturation of bile. Where cholic acid and ampicillin administration led to expansion of the deoxycholate pool, a rise in cholesterol saturation of bile ensued but, where the deoxycholate pool shrank, saturation fell (Carulli et al. 1981). Since the colon is the sole source of deoxycholate, these studies all point to the colon as perhaps an unexpected but nevertheless important factor determining cholesterol supersaturation of bile, and therefore gallstone risk. It is known that the coupling of bile acid and phospholipid (the detergents) with cholesterol secretion varies with different bile acids. Chenodeoxycholic acid alters it in favour of the detergents (Northfield et al. 1975), while deoxycholic acid not only suppresses chenodeoxycholic acid synthesis (Pomare \& Low-Beer 1975) but appears to shift the balance towards cholesterol excess. One would speculate the increased colonic deoxycholate absorption would be favoured by constipation, and by a colonic flora working in a relatively alkaline environment.

\section{Other nutritional factors}

With decreased bile flow, detergent output falls more than cholesterol secretion, and cholesterol saturation rises. Thus fasting up to $16 \mathrm{~h}$ increases cholesterol saturation of bile (Metzger et al. 1973; Williams et al. 1977; Mok et al. 1980) but thereafter hunger would seem to contract the gall-bladder and revive the enterohepatic circulation, for after $\mathrm{I} 6 \mathrm{~h}$ saturation falls again (Duane et al. 1976; Bloch et al. 1980). Indeed frequency of meals tended to be less in French women 
aged $20-35$ years with gallstones compared with matched controls (Capron et al. 198I).

Regular moderate alcohol $(30-40 \mathrm{~g} / \mathrm{d})$ reduces bile cholesterol saturation (Thornton et al. $1983 b$ ) and appears to protect against gallstones compared with teetotallers and occasional imbibers (Friedman et al. 1966; Sarles et al. 1969; Scragg et al. 1984).

\section{Conclusions}

There can be little doubt that nutritional factors are the principal reason for the high prevalence of gallstones in societies where much processed food is consumed. Epidemiological studies show that urbanization (Nagase et al. 1978) and migration to industrialized nations, lead to an increased prevalence of cholesterol-containing gallstones.

However, detailed nutritional studies, as so often, produce a very blurred picture of the important factors. They indicate that nutritional factors are more significant for gallstone disease in middle than in later life. Oral contraceptives provide an analogy; the eventual development of gallstones is similar in users and non-users, only contraceptive use brings them to light at a younger age (Royal College of General Practitioners' Oral Contraceptive Study, 1982). Of the various factors, obesity most consistently emerges as significant. Yet obesity alone is probably insufficient, for female obesity is common in rural Zimbabwe and Tonga (Heaton et al. 1977 ; E. W. Pomare, unpublished results) where gallstones appear to be rare. Gallstones often occur in slim women. Obesity and perhaps overnutrition need to act against a certain metabolic background. This metabolic disturbance leads to secretion of bile saturated with cholesterol as a necessary precondition for cholesterol gallstone formation. However, in some countries up to $40 \%$ of adults may secrete saturated bile without having gallstones (Sedaghat \& Grundy, r 980 ). It seems that a gall-bladder factor encouraging cholesterol nucleation needs to be added to the abnormal hepatic metabolism elaborating supersaturated bile before gallstones are formed. Whether this gall-bladder factor has a nutritional basis is unknown, but its persistence is probably the reason for the frequent recurrence of stones after medical dissolution (Dowling, 1983) and after surgical removal of stones through a cholecystotomy.

Lastly, as in many studies of the influence of life-style on disease, factors which appear to determine proneness of individuals in a population may not emerge as particularly significant in determining the proneness of the population as a whole.

\section{REFERENCES}

Ahlberg, J. ( 1979). Acta Chirurgica Scandinavica (Supplement 492), I-32.

Ahlberg, J., Angelin, B., Einarsson, K., Hellstrom, K. \& Leijd, B. (1979). Digestive Diseases and Sciences $24,459-464$.

Andersen, E. \& Hellstrom, K. (1980). Metabolism 29, 400-409.

Angelin, B., Einarsson, K., Ewerth, S. \& Leijd, B. ( 1981 ). Scandinavian Yournal of Gastroenterology 16, 1015-1019.

Bateson, M. C. (1980). Digestive Diseases and Sciences 25, 31 5-317. 
Bell, G. D., Lewis, B., Petrie, A. \& Dowling, R. H. (1973). British Medical Yournal ii, 520-522.

Bennion, L. J. \& Grundy, S. M. (1975). Fournal of Clinical Investigation 56, 996-101 1 .

Bloch, H. M., Thornton, J. R. \& Heaton, K. W. (1980). Gut 21, 1087-1089.

Burkitt, D. P. \& Tunstall, M. (1975). Journal of Tropical Medicine and Hygiene 78, 140-1 44.

Burnett, W. (1971). Tijdschrift voor Gastroenterologie 14, 79-89.

Capron, J. P., Delamarre, J., Herve, M. A., Dupas, L. P., Poulain, P. \& Descombes, P. (1981). British Medical Yournal 283, 1435 .

Carulli, N., Ponz de Leon, M., Loria, P., Iori, R., Rosi, A. \& Romani, M. (1981). Gastroenterology $81,539-546$.

Cleave, T. L. (1974). The Saccharine Disease. Bristol: Wright.

Dam, H., Prange, I., Krogh Jensen, M., Kallehauge, H. E. \& Fenger, H. J. (1971). Zeitschrift für Ernährungswissenschaft 10, 178-187.

DenBesten, L., Connor, W. E. \& Bell, S. (1973). Surgery 73, 266-273.

Dowling, R. H. (1983). Clinics in Gastroenterology 12, $125^{-1} 78$.

Duane, W. C., Ginsberg, R. L. \& Bennion, L. J. (1976). Fourmal of Lipid Research 1 7, 21 1-2 19.

Friedman, G., Kannel, W. \& Dawber, T. (1966). Fournal of Chronic Disease 19, 273-292.

Heaton, K. W. (1975). In Refined Carbohydrate Foods and Disease, pp. 179-184 [D. P. Burkitt and H. C. Trowell, editors]. London: Academic Press.

Heaton, K. W. (1979). In Gallstones, pp. 371-389 [M. M. Fisher, C. A. Goresky, E. A. Shaffer and S. M. Strasberg, editors]. New York: Plenum.

Heaton, K. W., Wicks, A. C. B. \& Yeates, J. (1977). In Bile Acid Metabolism in Health and Disease, pp. 1 97-202 [G. Paumgartner and A. Stiehl, editors]. Lancaster: MTP Press.

Hofmann, A. F., Grundy, F. M., Lachin, J. M., Lan, S.-P., Baum, R. A., Hanson, R. F., Hersh, T., Hightower, N. C. Jr, Marks, J. W., Mekhjian, H., Shaefer, R. A., Soloway, R. D., Thistle, J. L., Thomas, F. B., Tyor, M. P. \& National Co-operation Gallstone Study Group (1982). Gastroenterology 83, 738-752.

Kadziolka, R., Nilsson, S. \& Schersten, T. (1977). Scandinavian fournal of Gastroenterology I 2, 353-355.

Keen, H., Thomas, B. J., Jarrett, R. J. \& Fuller, J. H. (1979). British Medical Fournal i, $655-65_{5} 8$.

Lee, D. W., Gilmore, C. J., Bonorris, G. G., Cohen, H., Marks, J. W., Meiselman, M. S. \& Schoenfield, L. J. ( $\left(\mathrm{g}^{8} 3\right)$. In Bile Acids and Cholesterol in Health and Disease, pp. 237-238 [G. Paumgartner, A. Stiehl and K. W. Gerok, editors]. Lancaster: MTP Press.

Low-Beer, T. S. (1977). Clinics in Gastroenterology 6, 165-1 78 .

Low-Beer, T. S. \& Nutter, S. (1978). Lancet ii, 1063-1064.

Low-Beer, T. S. \& Pomare, E. W. (1975). British Medical fournal i, $43^{8-440 .}$

Mabee, T. M., Meyer, P., DenBesten, L. \& Mason, E. E. (1976). Surgery 79, ${ }_{460-468 .} 6$

McDougall, R. M., Yakymyshyn, L., Walker, K. \& Thurston, O. G. (1978). Canadian fournal of Surgery $21,433-435$.

Metzger, A. L., Adler, R., Heymsfield, S. \& Grundy, S. M. (1973). New England Foumal of Medicine 288, $333-33^{6}$.

Mok, H. Y. I., von Bergmann, K. \& Grundy, S. M. (I980). Gastroenterology 78, 1023-1033.

Nagase, M., Tanimura, H., Setoyama, M. \& Hikasa, Y. (1978). American fournal of Surgery 135 , $788-790$.

Newman, H. F. \& Northup, J. D. (1 959). International Abstracts of Surgery 1 09, I-1 3.

Northfield, T. C., La Russo, N. F., Hofmann, A. F. \& Thistle, J. L. (1975). Gut 16, I-1 7 .

Petitti, D. B., Friedman, G. D. \& Klatsky, A. L. (1981). New England Fournal of Medicine 304, $1396-1398$.

Pomare, E. W. \& Heaton, K. W. (1973). British Medical Fournal 4, 262-264.

Pomare, E. W., Heaton, K. W., Low-Beer, T. S. \& Espiner, H. J. (1976). American fournal of Digestive Diseases $2 \mathrm{I}, 52 \mathrm{I}-526$.

Pomare, E. W. \& Low-Beer, T. S. (1975). Clinical Science and Molecular Medicine 48, 31 5-32 I.

Royal College of General Practitioners' Oral Contraceptive Study (1982). Lancet ii, 957-959.

Sampliner, R. E., Bennett, P. H., Commess, L. J., Rose, F. A. \& Burch, T. A. (1970). New England fournal of Medicine 283, $135^{8-1} 3^{6} 4$.

Sarles, H., Chabert, C., Pommeau, Y., Save, E., Mauret, H. \& Gerolami, A. (1969). American fournal of Digestive Diseases 14, $531-537$.

Sarles, H., Crotte, C., Gerolami, H., Mule, A., Domingo, H. \& Hauton, J. (1971). Scandinavian fournal of Gastroenterology 6, 189-191. 
Scragg, R. K. R., McMichael, A. J. \& Baghurst, P. A. (1984). British Medical fournal 288, III3-1119.

Sedaghat, A. \& Grundy, S. M. (1980). New England fournal of Medicine 302, 1274-1277.

Smith, D. A. \& Gee, M. I. (1979). American fournal of Clinical Nutrition 32, $1519-1526$.

Sturdevant, R. A. L., Dayton, S. \& Pearce, M. L. (1973). New England fournal of Medicine 288, $24-27$.

Thornton, J. R., Emmett, P. M. \& Heaton, K. W. (1983a). Gut 2, 2-6.

Thornton, J. R. \& Heaton, K. W. (198I). British Medical Yournal 282, 1018-1020.

Thornton, J. R., Heaton, K. W. \& Macfarlane, D. G. (1981). British Medical Yournal 283, $1352-1354$.

Thornton, J. R., Symes, S. \& Heaton, K. W. (1983b). Lancet ii, 819-822.

van der Linden, W. (1961). Acta Chirurgica Scandinavica Supplement 269.

van der Linden, W. \& Bergman, F. (1977). Scandinavian fournal of Clinical Investigation 37, $74 \mathrm{I}-747$.

Watts, J. McK., Jablonski, P. \& Toouli, J. (1978). American Journal of Surgery r35, 32 I-324.

Werner, D., Emmett, P. M. \& Heaton, K. W. (1984). Gut 25, 269-274.

Williams, C. N., Morse, J. W. I., MacDonald, I. A. Kotoor, R. \& Riding, M. D. (1977). American fournal of Digestive Diseases 22, 189-194.

Zahor, Z., Sternby, N. H., Kagan, A., Uemera, K., Vanecek, R. \& Vichert, A. M. (I974). Scandinavian Yournal of Gastroenterology 9, 3-7. 